\title{
The Influence of the Precipitation Heat Treatment Temperature on the Metallurgical, Microstructure, Thermal Properties, and Microhardness of an Alpha Brass
}

\author{
Ignacio Rojas-Rodríguez ${ }^{1}$, Alberto Lara-Guevara ${ }^{2}$, Mauricio Salazar-Sicacha ${ }^{3}$, \\ Julio Cesar Mosquera-Mosquera3 ${ }^{3}$ Minerva Robles-Agudo',4, \\ Cristian Ramirez-Gutierrez ${ }^{5}$, Mario Rodríguez-García ${ }^{6}$ \\ ${ }^{1}$ División Industrial, Universidad Tecnológica de Querétaro, Querétaro, México \\ ${ }^{2}$ División de Posgrado, Facultad de Informática, Universidad Autónoma de Querétaro, Querétaro, México \\ ${ }^{3}$ Programa de Física, Universidad del Quindío, Armenia, Colombia \\ ${ }^{4}$ Catedras Conacyt, Universidad Tecnológica de Querétaro, Querétaro, México \\ ${ }^{5}$ Posgrado en Ciencia e Ingeniería de Materiales, Centro de Física Aplicada y Tecnología Avanzada, Universidad Nacional \\ Autónoma De México, Campus Juriquilla, Querétaro, México \\ ${ }^{6}$ Departamento de Nanotecnología, Centro de Física Aplicada y Tecnología Avanzada, Universidad Nacional Autónoma \\ de México, Campus Juriquilla, Querétaro, México \\ Email: irojasmx@yahoo.mx
}

How to cite this paper: Rojas-Rodríguez, I., Lara-Guevara, A., Salazar-Sicacha, M., Mosquera-Mosquera, J.C., Robles-Agudo, M., Ramirez-Gutierrez, C. and RodríguezGarcía, M. (2018) The Influence of the Precipitation Heat Treatment Temperature on the Metallurgical, Microstructure, Thermal Properties, and Microhardness of an Alpha Brass. Materials Sciences and Applications, 9, 440-454.

https://doi.org/10.4236/msa.2018.94030

Received: February 23, 2018

Accepted: April 23, 2018

Published: April 27, 2018

Copyright $\odot 2018$ by authors and Scientific Research Publishing Inc. This work is licensed under the Creative Commons Attribution International License (CC BY 4.0).

http://creativecommons.org/licenses/by/4.0/ c) (i) Open Access

\begin{abstract}
Metals obtain optimum conditions of metallurgical and physical properties through a heat treatment. Brass is one of the copper alloys which has many applications in everyday life and in the industry. Brass is one of the copper alloys which has many applications in everyday life and the industry. In this work, the influence of the precipitation heat treatment temperature on the metallurgical microstructure, structure, thermal properties, and microhardness of an alpha brass is analyzed. Samples were heat treated by precipitation for $2 \mathrm{~h}$ at $300^{\circ} \mathrm{C}, 400^{\circ} \mathrm{C}, 500^{\circ} \mathrm{C}, 600^{\circ} \mathrm{C}$, and $700^{\circ} \mathrm{C}$. The best mechanical properties were found at $500^{\circ} \mathrm{C}$ of precipitation heat treatment temperature. Specimens were characterized by scanning electron microscopy, X-ray diffraction, Vickers microhardness, photothermal radiometry, and photoacoustic to study the thermal diffusivity and conductivity, as well as the heat capacity. The inverse of the full width at the half maximum analysis showed that the crystallinity decreased as the precipitation heat treatment temperature increased. Metallurgical microstructure and microhardness were correlated to the precipitation heat treatment temperatures to determine the effect on the metallurgical and mechanical properties, as well as the effect on the thermal properties of alpha brass.
\end{abstract}




\section{Keywords}

Alpha Brass, Kunial Brass, Crystallinity, Photoacoustic, Precipitation Heat Treatment, X Ray Diffraction

\section{Introduction}

The importance of the use of metals from the discovery of iron to the industrial age can be attributed to specific properties. The application of metals depends on mechanical and metallurgical properties, optical properties, electrical and thermal conductivity, and corrosion resistance.

Metals have had a big relevance for the humanity development, facilitating the life and making possible technological advances still today. According to job requirements, metal properties and characteristics have been taken into account for the material selection.

Copper alloys can be adapted to a large number of applications. More than 400 copper alloys are known. Two of the best-known copper alloys are brass and bronze. Brass is a metal alloy made of copper and zinc [1], whose proportions can be modified to create a range of brasses with varying properties [2]. The formation of brass makes it a substitutional alloy i.e. atoms of the two constituents may be replaced each other within the same crystal structure [1].

High-strength brasses are suitable mainly for engineering areas where high strength to support heavy loads and/or high resistance to wear and corrosion are required. The main advantages of high-strength brasses are further improvement of mechanical properties by heat treatment as well as their low cost [3] [4]. Brass is nowadays considered as one of the most important copper-based alloys. In addition, due to the fact that the amount of zinc in such alloys can vary considerably, ranging from 5 to $45 \mathrm{wt} \%$, a wide variety of brass alloys with different technological properties for various commercial and industrial applications can be produced [5]. Ozgowiez et al. [6] examined the influence of the recrystallization annealing temperature on the microstructure and mechanical properties of brass $\mathrm{Cu} 30 \% \mathrm{Zn}$ subjected to cold deformation with a varying strain in the rolling process. The mechanical test showed that brass properties were deteriorated and plastic properties increased as the recrystallization temperature was increasing within the range of $400^{\circ} \mathrm{C}$ to $650^{\circ} \mathrm{C}$ [7].

Bailey (1967) studied the structure and strength of an alpha brass with $20 \%_{\mathrm{w}}$ $\mathrm{Zn} ; 6 \%{ }_{\mathrm{w}} \mathrm{Ni}$ and $1.5 \%_{\mathrm{w}}$ Al. Brass samples were subjected to solution heat treatment (SHT) at $800^{\circ} \mathrm{C}$ for $2 \mathrm{~h}$ following by quenching with water. After that, samples were heat treated by precipitation for $2 \mathrm{~h}$ at $300^{\circ} \mathrm{C}, 400^{\circ} \mathrm{C}, 500^{\circ} \mathrm{C}, 600^{\circ} \mathrm{C}$ and $700^{\circ} \mathrm{C}$. Best mechanical properties were obtained at $500^{\circ} \mathrm{C}$ PHT temperature [8].

This study is aimed to evaluate and characterize Kunial brass by scanning electron microscopy (SEM), X-ray diffraction (XRD), Vickers microhardness, and, photothermal radiometry (PTR) to determine the influence of the precipitation heat treatment (PHT) temperature on the metallurgical microstructure, 
thermal properties, and microhardness. Metallurgical microstructure and microhardness were correlated to the precipitation heat treatment temperatures to determine the effect on the metallurgical and mechanical properties, as well as the effect on the thermal properties of alpha brass.

\section{Experimental Methods}

\subsection{Materials}

The studied Kunial brass is a copper-zinc alloy plus nickel and corresponds to an alpha-brass with chemical composition $20 \% \mathrm{Zn}_{\mathrm{w}}, 6 \% \mathrm{Ni}_{\mathrm{w}}, 1.5 \% \mathrm{Al}_{\mathrm{w}}$, and the balance $\mathrm{Cu}$. Six samples were characterized; only one of them with SHT, as reference; the rest was treated at different PHT temperatures, as shown in Table 1. Samples were metallographically prepared with $240,320,400,600$, and 1000 grit sandpapers. Then, specimens were polished with $0.3 \mu \mathrm{m}$ alumina, and etched with $2 \mathrm{~g}$ of $\mathrm{K}_{2} \mathrm{Cr}_{2} \mathrm{O}_{7}, 8 \mathrm{~mL}$ of $\mathrm{H}_{2} \mathrm{SO}_{4}, 4 \mathrm{~mL}$ of $\mathrm{NaCl}$ saturated solution and 100 $\mathrm{mL}$ of distilled $\mathrm{H}_{2} \mathrm{O}$.

\subsection{SEM Analysis}

SEM analysis was carried out using a JPG scanning electron microscopy equipped with a Thermo Noran detector. The accelerating voltage was $20.0 \mathrm{kV}$.

\subsection{XRD Analysis}

The XRD analysis was carried out using a Siemens diffractometer Crystaloflex 5000 operating at $35 \mathrm{~K}, 15 \mathrm{~mA}$ with $\mathrm{CuK}_{\alpha}$ line at room temperature. The experimental FWHM was analyzed using a Dataflex program. XRD patterns served as an aid to study the crystalline phases, as well as the shift of the sample characteristic peaks. After a wide scanning from $20^{\circ}$ to $105^{\circ}$, the main peaks were measured inside a short-step scanning of $0.005^{\circ} /$ step to enhance the differences between peaks.

\subsection{Vickers Microhardness}

Sixteen indentations were practiced on each polished brass sample, according to ASTM E92. One Leco Model LM300AT Vickers microhardness tester at $100 \mathrm{~g}$ load, according to ASTM-E70, was used [9].

\subsection{Thermal Diffusivity}

The thermal diffusivity was performed in an open photoacoustic cell (OPC) [5]. The OPC setup is shown in Figure 1. Sample thicknesses are described in Table 1. An Electret microphone was used where samples were placed on top of the microphone. A blue laser of $450 \mathrm{~nm}$ wavelength was modulated with a lock-in SR830 and focused onto the sample surface. A simulation frequency modulation from $15 \mathrm{~Hz}$ to $400 \mathrm{~Hz}$ was used. Sample data were collected by photoacoustic technique using a lock-in amplifier interfaced with a PC to observe amplitude and phase signal behaviors [10]. 


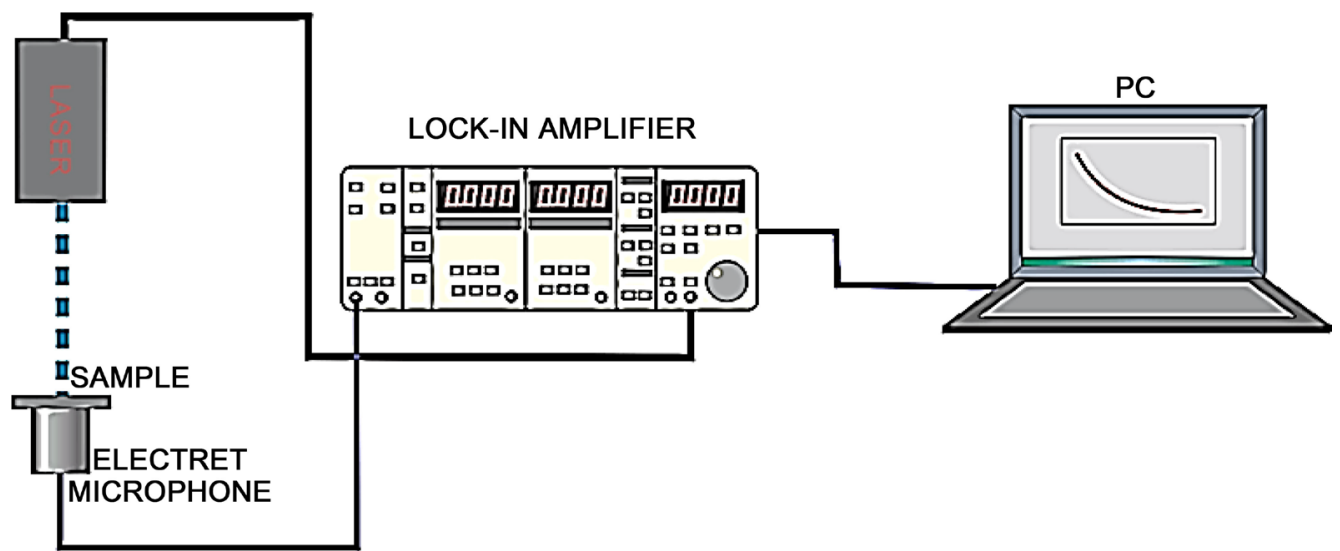

Figure 1. Experimental OPC set-up.

Table 1. PHT temperature, thickness, and Vickers microhardness of Kunial brass samples.

\begin{tabular}{cccc}
\hline Sample & PHT temperature ${ }^{\circ} \mathrm{C}$ & Thickness $(\mathrm{m})$ & Reported Vickers microhardness $^{8}$ \\
\hline SHT & NA & 387 & 72 \\
P300 & 300 & 392 & 82 \\
P400 & 400 & 375 & 140 \\
P500 & 500 & 392 & 201 \\
P600 & 600 & 398 & 162 \\
P700 & 700 & 401 & 135 \\
\hline
\end{tabular}

The pressure at the photoacoustic gas chamber was calculated using a thermal diffusion model [11] with the simplification for the thermally thick and optically opaque regime [12] according to the following equation:

$$
V_{O P C}=\frac{A}{f} \mathrm{e}^{-\sqrt{\frac{f}{f_{c}}}}
$$

where, $A$ is a constant that contains geometric parameters including factors as gas thermal properties, light beam intensity, and room temperature; $f$ is the frequency scan and $f_{c}$ is the cutoff which separates thick and thin regimens. This cutoff is correlated to thermal diffusivity $\alpha$ and the sample thickness $l$ as in the following equation [12]:

$$
\alpha=\pi l^{2} f_{c}
$$

\subsection{Heat Capacity}

The heat capacity was determined using the thermal relaxation method [5]. A thermocouple was connected to the back side of the sample. The source was a blue laser of $450 \mathrm{~nm}$ wavelength, which was focused onto the sample surface with a continuous incidence and uniformly. The complement of the system was a computer to process acquired data. Conduction and convection energy losses were reduced by a vacuum disposal, thereby mainly ensuring a radiation heat transfer [13]. The temperature variation was determined by 


$$
\Delta T(t)=\frac{P_{0}}{\eta}\left(1-\mathrm{e}^{-\tau / T}\right)
$$

$\tau$ value is related to the heat capacity by

$$
\rho C_{p}=\frac{8 \varepsilon \sigma T_{0}^{3}}{l_{m}}
$$

where $\varepsilon$ is the thermal emissivity that is considered 1 in this case, $\sigma$ is Stefan Boltzmann constant, $\mathrm{T}_{0}$ is the temperature, and $l_{m}$ is the thickness. The thermal conductivity is related to the heat capacity and thermal diffusivity by

$$
k=\alpha \rho C_{p}
$$

\subsection{PTR}

PTR was used to obtain sample thermal images. A high-power semiconductor laser (450 nm wavelength, $300 \mathrm{~mW}$ ) was used. The laser beam was collimated, and then it was focused onto the surface of the sample with a $40 \mu \mathrm{m}$ spot size using a gradium lens. The modulated infrared radiation from the excited surface was collected and collimated by two off-axis paraboloid mirrors, and then, it was focused onto a Judson Model J15D12-M204 HgCdTe detector, which was cooled by liquid nitrogen. The detector signal was amplified by a low-noise preamplifier, and then, it was sent to a lock-in amplifier SRS-850 which was interfaced with a PC. A XYZ microstages was used to obtain PTR amplitude and phase images [14].

Thermal images were obtained by scanning an area of $2 \times 2 \mathrm{~mm}$ from each sample. SEM images were compared to the PTR images obtained in the same area. Images were taken at 40 lines, 50 points per line, and at $50 \mu \mathrm{m}$ between points and lines, according to the methodology proposed elsewhere [8] [10] [14] [15]. The PTR method comprises the optical excitation of the sample by a modulated source, as well as the detection of the recombination-induced infrared emission while some Planck-mediated emissions are filtered. PTR completely covers the thermal infrared emission band $(2-12 \mu \mathrm{m})$. Two information channels were used: PTR amplitude and phase signals obtained from a highly focused laser beam $(40 \mu \mathrm{m})$, and recently developed theoretical [15] and computational techniques [10].

The thermal wave generated by the absorption of laser radiation at the sample surface becomes attenuated at a distance $\mu$ and only information due to changes in the thermal properties of the surface of the sample is obtained. The thermal length is defined by

$$
\mu=\sqrt{\frac{\alpha}{\mu f}}
$$

where $\alpha$ is the thermal diffusivity of the samples and $f=\omega / 2 \pi$.

The PTR amplitude generated in the sample due to the absorption of modulated laser can be described by the following equation [8]: 


$$
T(x, t)=\frac{I_{o}}{2 \varepsilon \sqrt{\omega}} \exp \left(-\frac{x}{\mu}\right) \cos \left(\omega t-\frac{x}{\mu}+\frac{\pi}{4}\right)
$$

where $\omega$ is the angular frequency, $I_{0}$ is the laser intensity, $x$ is the sample thickness, and $\varepsilon$ is the thermal effusivity. Note, that the pre-factor in Equation (7) is constant for a fixed modulation frequency $f=\omega / 2 \pi$.

The measured PTR amplitude signal is proportional to the reciprocal of the thermal effusivity, while the PTR phase lag will be proportional to the $\mathrm{x} / \mu$ term. It is well known that the thermal effusivity and the thermal diffusivity are dependent parameters from the thermal wave propagation which determines the material inertia. The thermal effusivity is a significant heating periodic surface and a heat transport parameter because it represents the dissipated heat energy in the solid material depending on the temperature change at the beginning of the periodic warming process. The thermal effusivity is related to Equation (6) by the diffusivity coefficient $(\alpha)$, as shown in the following equation:

$$
\varepsilon=\frac{k}{\sqrt{\alpha}}=\sqrt{k \rho c}
$$

where $k$ is the thermal conductivity, $\rho$ is the material density, and $c$ is the specific heat at a constant volume.

\section{Results and Discussion}

\subsection{SEM Metallurgical Microstructure}

Brass is characterized by its metallurgical microstructure depending on the $\mathrm{Zn}$ content. The microstructure of commercial brass is formed by $\alpha, \alpha+\beta$, and $\gamma+$ $\beta$ phases. More metallurgical microstructures can be formed as $\gamma, \gamma+\varepsilon$, and $\varepsilon+$ $\eta$. This study was focused on the $\alpha$ brass.

Figure 2 shows the metallurgical microstructure of studied brass samples. Figure 2(a) shows the microstructure of the SHT sample with uniform equiaxial grains and twin grains as a result of the heat treatment that produced a recrystallization of the $\alpha$ phase brass. Figure 2(b) shows little metallurgical microstructure changes, similarly to the SHT sample. Figure 2(c) illustrates differences in the grain distribution of the $\mathrm{P} 400$ sample mainly in the grain boundary, which is thicker than in SHT and P300 samples due to the precipitation started at $400^{\circ} \mathrm{C}$. The P500 sample shows in Figure 2(d) still little changes, however small precipitates at grain boundaries were observed at 2500X magnification. A microstructural comparison among P300, P400, and P500, samples showed grain size differences. P300 and P400 samples had an incipient state of precipitation, while the precipitation definitively was detected at the grain boundary of the P500 sample [8]. Figure 2(e) shows significant differences at grain boundaries of the P600 sample, where an increment of precipitates was observed. P700 sample showed in Figure 2(f) an over aged and reveled precipitations at the grain boundary and inside grains. That means that the precipitation increased with the temperature. The increment of precipitates as the temperature increased was a 

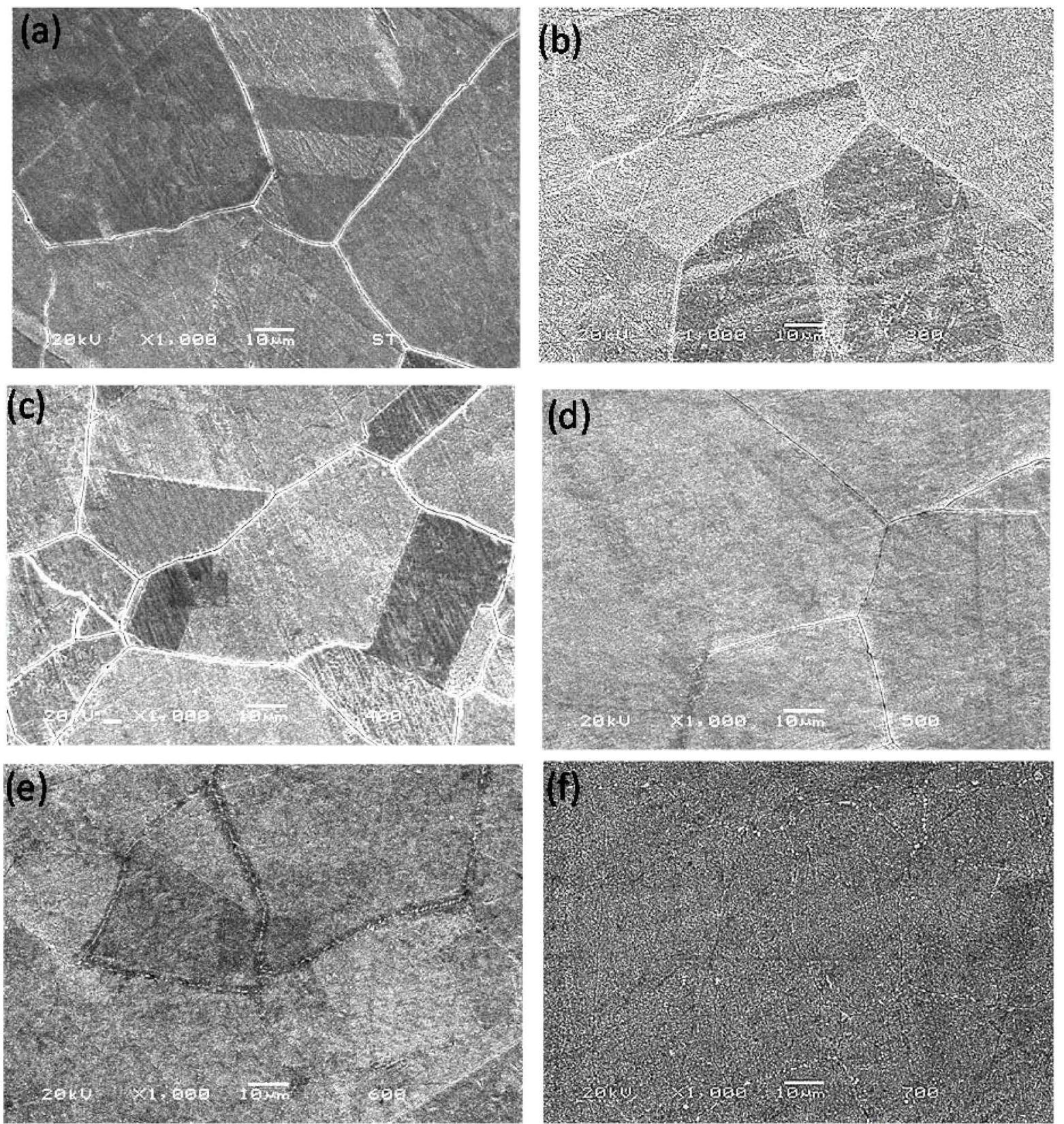

Figure 2. Brass metallurgical microstructure, 1000X magnification of samples (a) SHT, (b) P300, (c) P400, (d) P500, (e) P600, and (f) P700.

result of the phase separation. There was a thermal transformation process produced by the crystalline rearrangement.

\subsection{XRD Analysis}

Structural changes in the crystalline quality occurred as a consequence of PHT temperatures. Figure 3(a) shows XRD brass sample patterns. Crystalline orientations (111) and (200) were identified by using the powder diffraction file (PDF) 04-0836 [15]. The orientation (111) of Figure 3(b) showed the highest intensity in all cases [16] [17] [18] [19]. P400, P500, P600, and P700 samples had 
a small displacement on both planes. The inset of Figure 3(b) showed a new peak about at $2 \theta=44.6^{\circ}$ in P400, P500, P600, and P700 samples. The new peak represents the precipitation of an intermetallic compound identified as $\mathrm{Cu}_{3} \mathrm{Zn}^{19}$ resultant of the over aged due to the PHT temperature increase. The displacement can be explained as a consequence of the crystalline rearrangement at different PHT. Figure 3(c) illustrates FWHM changes as a result of the PHT temperature at the characteristic peak of the plane (111). The inverse of the full width at the half maximum $\left(\mathrm{FWHM}^{-1}\right)$ is directly related to the sample crystalline quality, and in this case, gives valuable information about the effect of the
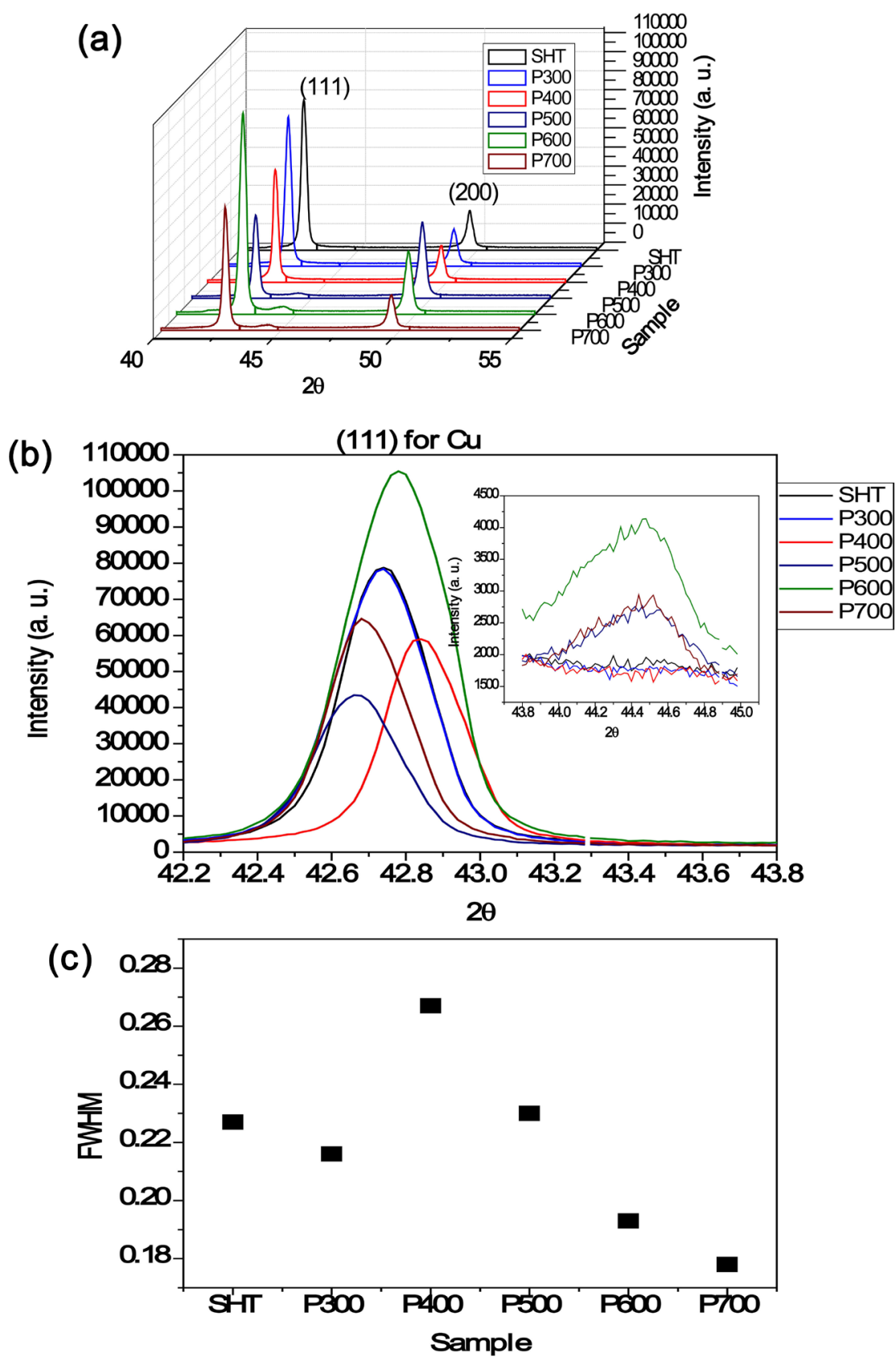

Figure 3. XRD of $\alpha$-brass samples (a) crystallographic planes (111) and (200), (b) plane (111) with inset showing a new peak about at $2 \mathrm{q}=44.6^{\circ}$, and (c) FWHM changes. 
heat treatment in the structure and microstructure [16] [17]. The lowest crystallinity corresponded to the P400 sample, while the best to the P600 sample. The P400 sample had a slow precipitation because precipitates began to migrate to grain boundaries at $400^{\circ} \mathrm{C}$ affecting its crystallinity. The optimum precipitation was reached at $500^{\circ} \mathrm{C}$.

\subsection{Thermal Properties}

Thermal diffusivity, conductivity, and heat capacity results are shown in Table 2.

In Figure 4(a) and Figure 4(b) the lowest diffusivity and conductivity values

Table 2. Thermal diffusivity and conductivity, heat capacity, and Vickers microhardness of Kunial brass samples.

\begin{tabular}{ccccc}
\hline Sample & $\alpha\left(\mathrm{cm}^{2} / \mathrm{s}\right)$ & $\rho \mathrm{C}\left(\mathrm{J} / \mathrm{m}^{3} \mathrm{~K}\right)$ & $k(\mathrm{~W} / \mathrm{m} \cdot \mathrm{K})$ & Vickers Microhardness \\
\hline SHT & 0.242 & $3.49 \times 10^{6}$ & 84.46 & 83.7 \\
P300 & 0.463 & $2.60 \times 10^{6}$ & 120.46 & 92.1 \\
P400 & 0.415 & $2.55 \times 10^{6}$ & 105.44 & 121.2 \\
P500 & 0.339 & $2.77 \times 10^{6}$ & 93.32 & 200.6 \\
P600 & 0.508 & $2.42 \times 10^{6}$ & 122.42 & 154.2 \\
P700 & 0.587 & $2.70 \times 10^{6}$ & 158.63 & 133.5 \\
\hline
\end{tabular}
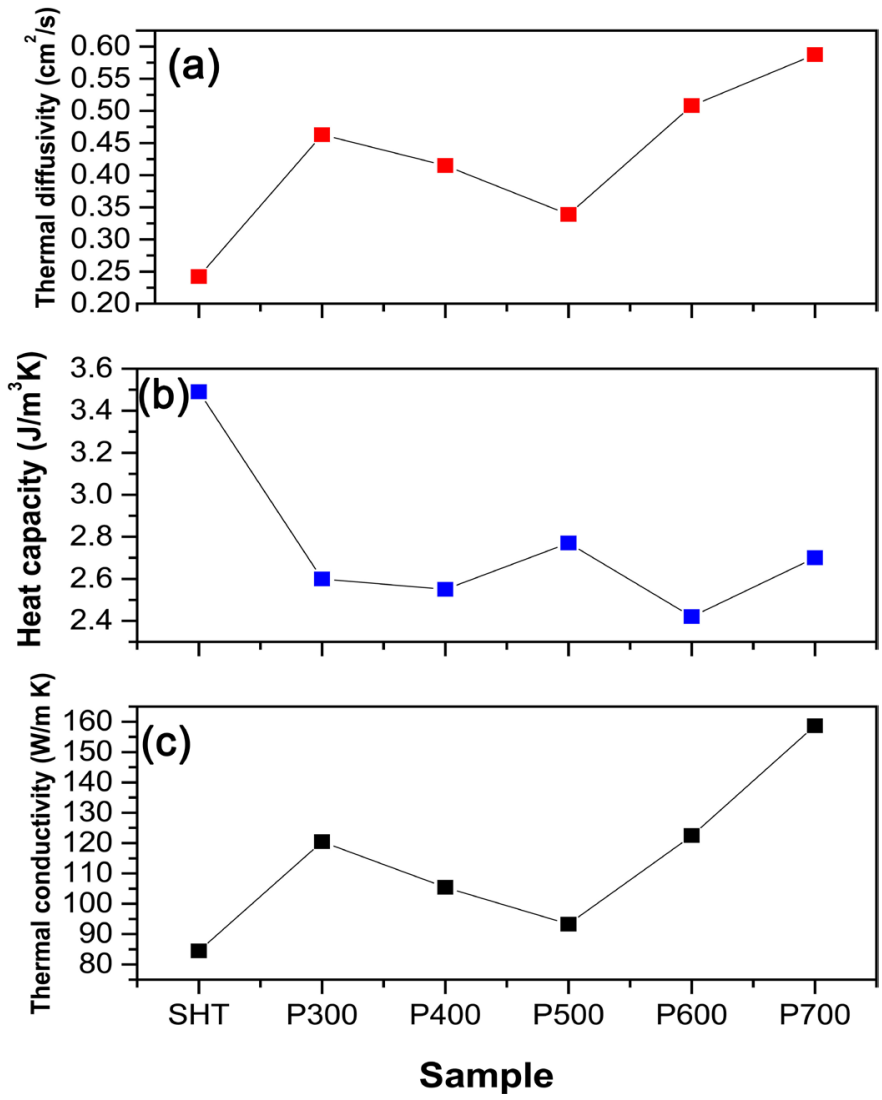

Figure 4. Thermal properties of brass samples studied (a) diffusivity; (b) heat capacity; (c) conductivity. 
corresponded to the SHT sample. Diffusivity and conductivity values increased at $300^{\circ} \mathrm{C}$. Diffusivity and conductivity values decreased from $400^{\circ} \mathrm{C}$ to $500^{\circ} \mathrm{C}$. Diffusivity and conductivity values increased again at $600^{\circ} \mathrm{C}$. The highest diffusivity and conductivity values were reached at $700^{\circ} \mathrm{C}$. In Figure 4 (c) the highest heat capacity value was for the SHT sample. The heat capacity value decreased from $300^{\circ} \mathrm{C}$ to $400^{\circ} \mathrm{C}$. The heat capacity value increased again at $500^{\circ} \mathrm{C}$ and reached the lowest value at $600^{\circ} \mathrm{C}$, but increased at $700^{\circ} \mathrm{C}$. The noticed behavior was that as diffusivity and conductivity increased the heat capacity trended to decrease. It can be explained by the thermal treatment due to the temperature increased, the grain size increased, and this had an effect on diffusivity and conductivity. The heat capacity decreased due to the PHT effect because intermetallic precipitates migrated to grain boundaries affecting the heat capacity.

\subsection{Vickers Microhardness and FWHM-1}

Figure 5(a) illustrates Vickers microhardness results. The lowest value corresponded to the SHT sample, while the highest value to the P500 sample. As the PHT temperature increased the Vickers microhardness decreased due to recrystallization and precipitation phenomena. The precipitation had a little effect from $300^{\circ} \mathrm{C}$ to $400^{\circ} \mathrm{C}$. However, the P500 sample reached the highest Vickers microhardness value at $500^{\circ}$. P600 and P700 samples showed that as the PHT temperature increased, the microhardness decreased due to the over aged.

In Figure 5(b) the $\mathrm{FWHM}^{-1}$ increased as the PHT temperature increased. As the Vickers microhardness decreased the crystallinity quality increased. The
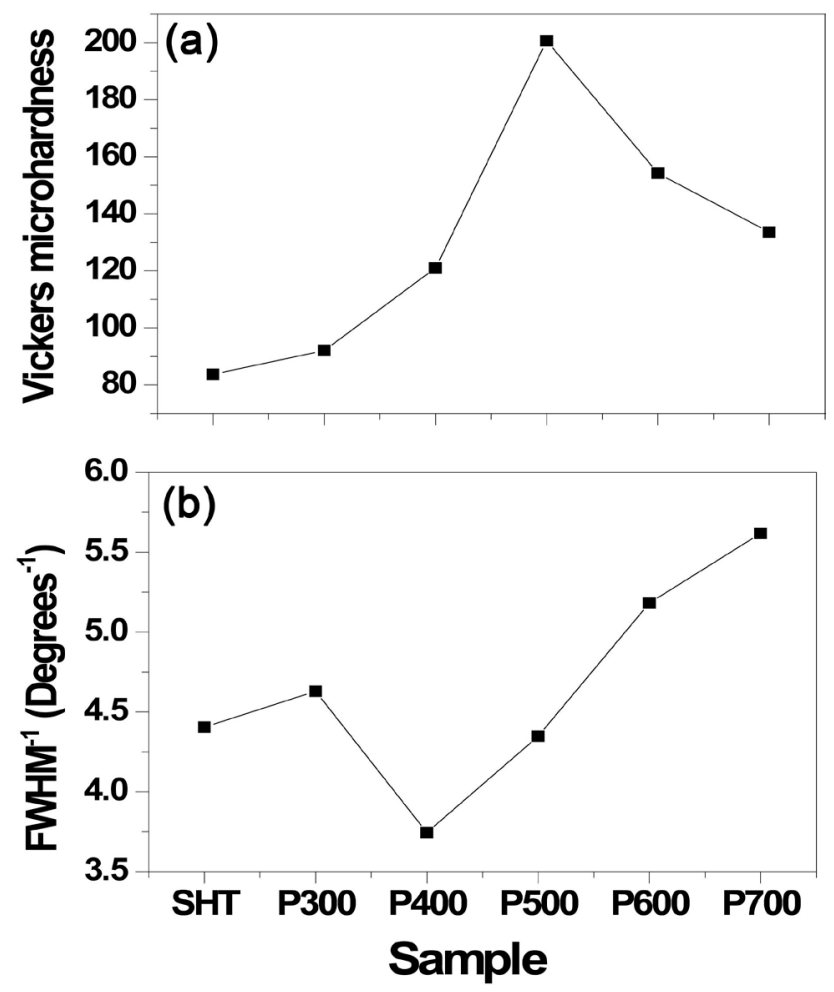

Figure 5. Results of Brass samples studied. (a) Vickers microhardness; (b) FWHM ${ }^{-1}$. 
lowest $\mathrm{FWHM}^{-1}$ value was at $400^{\circ} \mathrm{C}$, and then, it trended to increase as the PHT temperature increased. The crystalline quality improved as the PHT temperature increased. In spite of the highest Vickers microhardness value was reached at $500^{\circ} \mathrm{C}$ (P500), higher temperatures caused that the Vickers microhardness trended to decrease. It is interesting to observe that at $600^{\circ} \mathrm{C}$ the Vickers microhardness decreased, but the crystalline quality $\left(\mathrm{FWHM}^{-1}\right)$ improved as the PHT temperature increased. The Vickers microhardness decreased at $600^{\circ} \mathrm{C}$ as a result of a diffusive process due to the slow cooling temperature. The diffusive processes produced a recrystallization improving the crystalline quality.

\subsection{PTR Images}

PTR images are shown in Figure 6. In Figure 6(a) the amplitude increased as
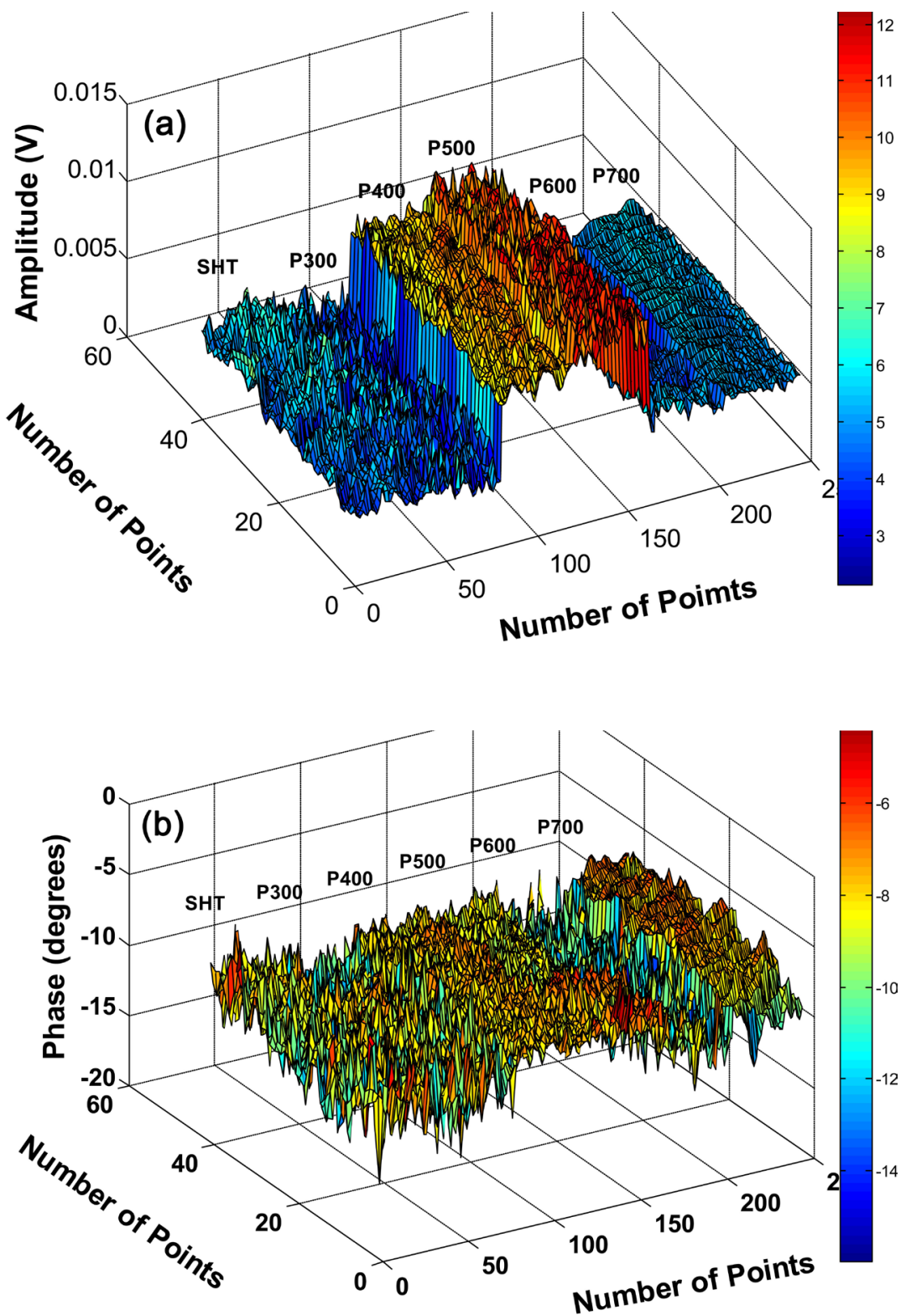

Figure 6. Photothermal images (a) amplitude and (b) phase. 
the PHT temperature increased until the highest signal at $500^{\circ} \mathrm{C}$. After that, amplitude signals decreased as the temperature increased until the lowest value at $700^{\circ} \mathrm{C}$. However, no large phase signal changes were observed in Figure 6(b).

As mentioned above the P500 sample showed the highest Vickers microhardness and the optimum precipitation, while the lowest Vickers microhardness corresponded to the P700 sample. Figure 7 shows the comparison among the Vickers microhardness and PTR amplitude and phase signals. Figure 7(a) illustrates the Vickers microhardness trend. In Figure 7(b) the amplitude behavior was similar to the hardness pattern because the PTR signal was related to brass structural changes. The maximum PTR amplitude signal was reached at $500^{\circ} \mathrm{C}$, that is, the optimum PHT temperature which corresponded to the maximum Vickers microhardness of the studied brass [20]. In Figure 7(c) the phase signal behavior did not show large changes as in the amplitude signal. The highest PTR

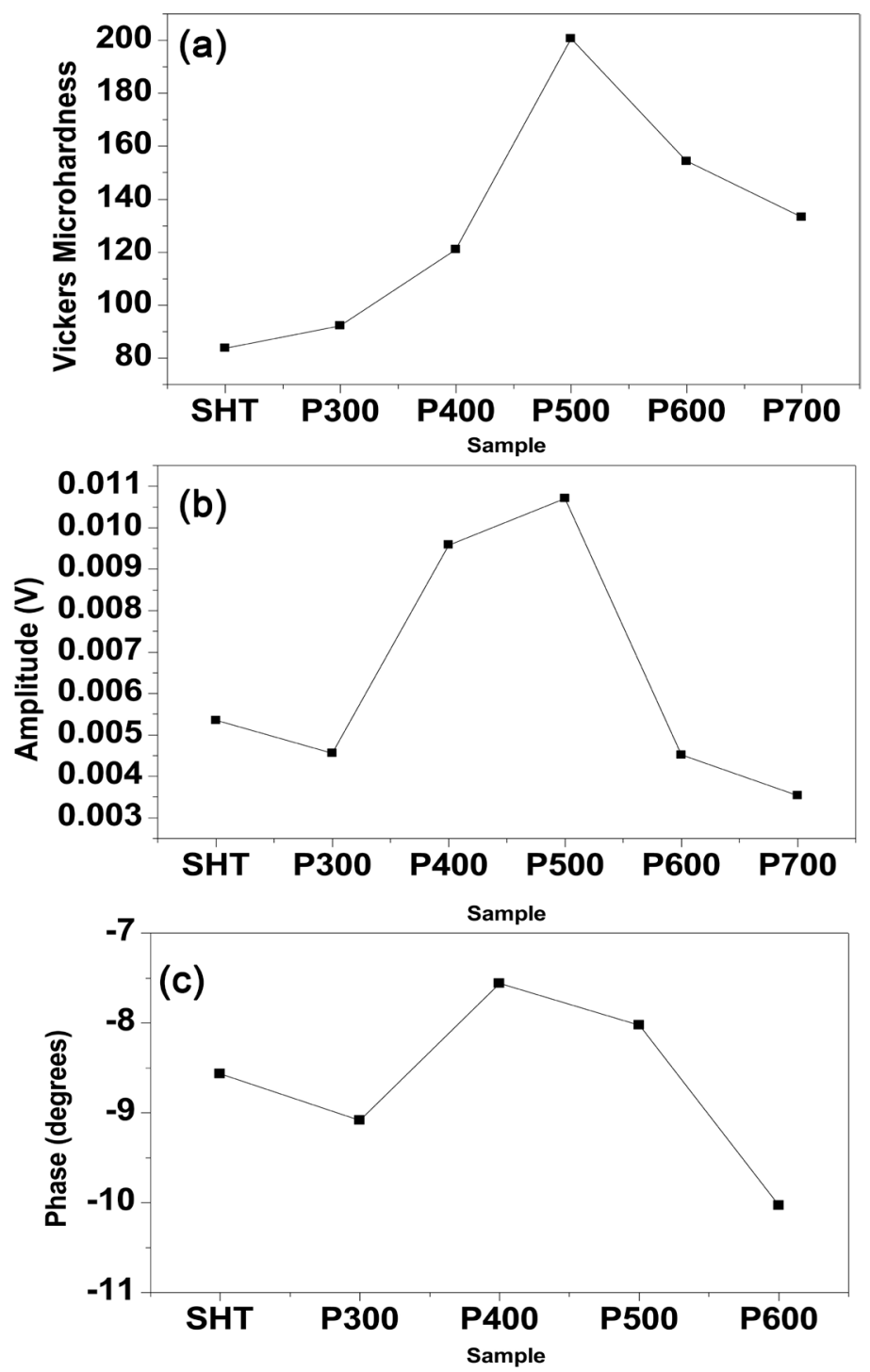

Figure 7. Comparison among, (a) Vickers microhardness and PTR, (b) amplitude and (c) phase signals. 
phase signal corresponded to the SHT sample, while the lowest PTR phase signal was observed at $700^{\circ} \mathrm{C}$. This means that the PTR amplitude signal was more sensitive than the PTR phase signal to observe the effect of the PHT temperature on $\alpha$ brass thermal, structural and Vickers microhardness properties.

\section{Summary}

1) The PHT temperature affected metallurgical, thermal and mechanical properties of Kunial brass samples.

2) PHT temperature variation produced crystalline rearrangement with precipitates at the grain boundaries. The XRD analysis showed a displacement at the plane (111) of P400 and P500 samples, as a result of the crystalline rearrangement between 400 and $500^{\circ} \mathrm{C}$ of PHT temperatures.

3) The FWHM analysis showed that thermal diffusivity and conductivity increased as the PHT temperature increased due to the grain size growth.

4) A marked correlation was found between the FWHM and the diffusivity. The diffusivity increased as the $\mathrm{FWHM}^{-1}$ increased. The highest diffusivity corresponded to $700^{\circ} \mathrm{C}$, while the lowest to the SHT sample.

5) The PHT temperature at $500^{\circ} \mathrm{C}$ produced the highest Vickers microhardness value. Vickers microhardness trended to decrease over $500^{\circ} \mathrm{C}$ of PHT temperature due to the over precipitation and sample oxidation.

6) The PTR amplitude behavior was similar to the Vickers microhardness pattern because the PTR signal was related to brass structural changes. The maximum PTR amplitude signal was reached at $500^{\circ} \mathrm{C}$, that is, the optimum PHT temperature which corresponded to the maximum Vickers microhardness.

7) The PTR amplitude signal was more sensitive than the PTR phase signal to observe the effect of the PHT temperature on $\alpha$ brass thermal, structural and Vickers microhardness properties.

\section{Acknowledgements}

The authors want to thank M. en Q. Alicia del Real and Dra. Beatriz Millan-Malo for the technical support of SEM and X-ray diffraction respectively. M. Robles-Agudo thanks Catedras CONACYT. The authors thank the financial support from CONACYT project number 256923.

\section{References}

[1] Copper Development Association (2004) Brass in Focus, 177, 1-4. http://copperalliance.org.uk/docs/librariesprovider5/resources/pub-177-brass-in-fo cus-pdf.pdf?Status $=$ Master\&sfvrsn $=0$

[2] Khurmi, R.S. and Gupta, J.K. (2004) Engineering Designer, 30, 6. https://es.slideshare.net/aliazam900/a-textbook-of-machine-design-by-rskhurmi-an d-jkgupta-44120476

[3] Waheed, A. and Ridley, N. (1994) Microstructure and Wear of Some High-Tensile Brasses. Journal of Materials Science, 29, 1692-1699. https://doi.org/10.1007/BF00368948 
[4] Sadykov, F.A., Barykin, N.P. and Aslanyan, I.R. (1999) Wear of Copper and Its Alloys with Submicrocrystalline Structure. Wear Volumes, 225-229, 649-655. https://doi.org/10.1016/S0043-1648(98)00374-3

[5] Panagopoulos, C.N., Georgiou, E.P. and Simeonidis, K. (2012) Lubricated Wear Behavior of Leaded $\alpha+\beta$ Brass. Tribology International, 50, 1-5. https://doi.org/10.1016/j.triboint.2011.12.016

[6] Ozgowicz, W., Kalinowska, E.O. and Grzegorczyk, B. (2010) The Microstructure and Mechanical Properties of the Alloy $\mathrm{Cu}-30 \% \mathrm{Zn}$ after Recrystallizing Annealing. Journal of Achievements in Materials and Manufacturing Engineering, 40, 15-25. http://jamme.acmsse.h2.pl/papers_vol40_1/4012.pdf

[7] Igelegbai, E.E., Alo, O.A., Adeodu, A.O. and Daniyan, I.A. (2017) Evaluation of Mechanical and Microstructural Properties of $\alpha$-Brass Alloy Produced from Scrap Copper and Zinc Metal through Sand Casting Process. Journal of Minerals and Materials Characterization and Engineering, 5, 18-30. https://file.scirp.org/pdf/JMMCE_2016122014370253.pdf https://doi.org/10.4236/jmmce.2017.51002

[8] Bailey, A.R. (1967) The Structure and Strength of Metals, Annotated Metallographic Specimens. Gatwick Press Ltd., Betchworth, 75-88.

http://www.worldcat.org/title/structure-and-strength-of-metals-an-elementary-prac tic-

al-course-involving-the-correlation-of-microstructure-and-properties-in-32-special ly-prepared-specimens/oclc/299573857

[9] ASTM E92-82(2003)e2 (2003) Standard Test Method for Vickers Hardness of Metallic Materials, Subcommittee: E28.06, ASTM International, 1-9.

http://метротест.pф/upload/gost/ASTM_E92.pdf

[10] Dias, D.T., Bedeschi, V.C., Ferreira da Silva, A., Nakamura, O., Castro-Meira, M.V. and Trava-Airoldi, V.J. (2014) Photoacoustic Spectroscopy and Thermal Diffusivity Measurement on Hydrogenated Amorphous Carbon Thin Films Deposited by Plasma-Enhanced Chemical Vapor Deposition. Diamond \& Related Materials, 48, 1-5. https://doi.org/10.1016/j.diamond.2014.06.003

[11] Lara-Guevara, A., Rojas-Rodríguez, I., Ortiz-Echeverri, C.J., Robles-Agudo, J.M. and Rodríguez-García, M.E. (2017) Thermal, Structural, and Microstructural Characterization of Eutectoid Steel at Different Heat Treatments. Journal of Materials Research, 32, 2202-2209. https://doi.org/10.1557/jmr.2017.47

[12] Lara-Guevara, A., Ortiz-Echeverri, C.J., Rojas-Rodriguez, I., Mosquera-Mosquera, J.C., Ariza-Calderón, H., Ayala-Garcia, I. and Rodríguez-García, M.E. (2016) Microstructural, Structural, and Thermal Characterization of Annealed Carbon. International Journal of Thermophysics, 37, 99. https://doi.org/10.1007/s10765-016-2105-6

[13] Demkó, L., Kézsmárki, I., Csontos, M., Bordács, S. and Mihály, G. (2010) Improved Thermal Relaxation Method for the Simultaneous Measurement of the Specific Heat and Thermal Conductivity. European Physics Journal B, 74, 27-33. https://doi.org/10.1140/epjb/e2010-00055-0

[14] Rojas-Rodríguez, I., Jaramillo-Vigueras, D., Velázquez-Hernández, R., Del Real, A., Serroukh, I., Baños, L., García, J. and Rodríguez-García, M.E. (2008) Thermal and Structural Characterization of Copper-Steel Bonding Interfaces Produced by Impact Welding. Materials and Manufacturing Processes, 23, 823-828. https://doi.org/10.1080/10426910802384672

[15] Rosencwaig, A. and Gersho, A. (1976) Theory of the Photoacoustic Effect with Sol- 
ids. Journal of Applied Physics, 47.

[16] Swanson, H.E., Gilfrich, T. and Ugrinie, M. (1955) Standard X-Ray Diffraction Powder Patterns. United States National Bureau of Standards, 539, 3. https://catalog.hathitrust.org/Record/001481228

[17] Lara-Guevara, A., Rojas-Rodríguez, I., Velázquez-Hernández, R., Jaramillo-Vigueras, D., del Angel-Sánchez, K. and Rodríguez-García, M.E. (2017) Photothermal, Structural, and Microstructural Characterization of SAE4320H Automotive Steel. Journal of Materials Engineering and Performance, 26, 2040-2046.

https://doi.org/10.1007/s11665-017-2633-7

[18] Hong, H.L., Wang, Q., Dong, C. and Liaw, P.K. (2014) Understanding the Cu-Zn Brass Alloys Using a Short-Range-Order Cluster Model: Significance of Specific Compositions of Industrial Alloys. Scientific Reports, 1-4.

[19] Ganesh, P., Nagpure, D.C., Gupta, R.K. and Kukreja, L.M. (2015) Non-Destructive Micro-Structural Characterization of Metallic Specimens with a Portable X-Ray Diffraction Based Residual Stress Analyzer. Studies of Engineering Technology, 2, 22-32. https://doi.org/10.11114/set.v2i1.795

[20] Guo, X., Sivagurunathan, K., Garcia, J.A., Mandelis, A., Giunta, A. and Milletari, S. (2009) Laser Photothermal Radiometric Instrumentation for Fast in-Line Industrial Steel Hardness Inspection and Case Depth Measurements. Applied Optics, 48, 11-22. https://doi.org/10.1364/AO.48.000C11 